International Journal of Current Advanced Research

ISSN: O: 2319-6475, ISSN: P: 2319 - 6505, Impact Factor: SJIF: 5.995

Available Online at www.journalijcar.org

Volume 6; Issue 4; April 2017; Page No. 3066-3071

DOI: http://dx.doi.org/10.24327/ijcar.2017.3071.0183

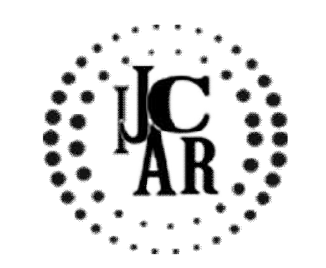

Review Article

\title{
ULTRASONICS IN MORDERN ENDODONTIC PRACTICE- A REVIEW
}

\author{
Samyukta $S$ and Pradeep S
}

Saveetha Dental College, PH Road, Chennai-600077

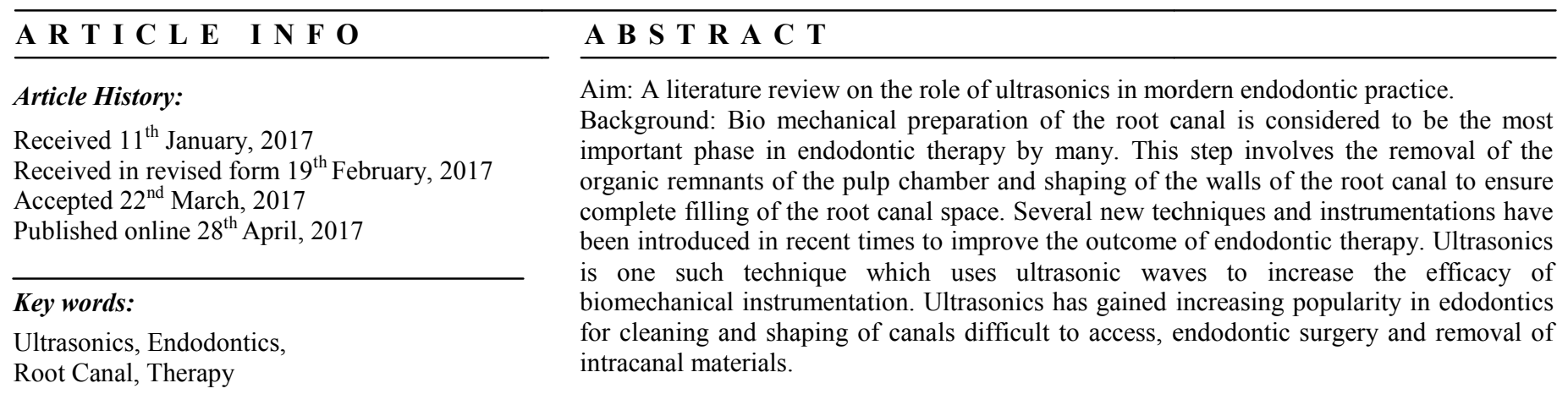

Copyright $(2017$ Samyukta $\boldsymbol{S}$ and Pradeep S. This is an open access article distributed under the Creative Commons Attribution License, which permits unrestricted use, distribution, and reproduction in any medium, provided the original work is properly cited.

\section{INTRODUCTION}

The evolution of dentistry is strongly correlated to the development of science and technology. Over the past few decades, endodontic treatment has benefited from the development of new techniques using newer instruments like the operating microscope and ultrasonics, which have widened the scope of endodontic therapy. Using ultrasonics in general dentistry practice, and particularly in endodontics, the predictability of treatment and prognosis has improved, when compared to the classical procedures while delivering superior quality and efficiency.

When ultrasound was introduced in dentistry, about 50 years ago, it was discovered that it was able to cut with the aid of an abrasive slurry composed of aluminum oxide (1-3). It was in 1950 that dentists uncovered the following advantages of dental cavity preparation with ultrasound:

1. Cutting of the tooth with very light pressure;

2. Absence of pain in the majority of the procedures;

3. Absence of harmful effect on the pulp;

4. Precision of cut and excellent quality of finishing.

\section{The most important advantages are}

1. Minimum noise; absence of pain in the great majority of the cases, preventing the use of anaesthesia;

2. Total visibility and access;

3. Cutting precision;

4. Minimally invasive preparation;

*Corresponding author: Samyukta S

Saveetha Dental College, PH Road, Chennai-600077
5. Selective cutting of hard materials; it does not cut soft materials, as gingiva or tongue;

6. It minimizes the bleeding;

7. It does not add residues on the tip, facilitating the cleanness;

8. It minimizes the smear layer

Disadvantages: It cannot be used only selectively in patients who use pace-maker as well as the handpiece is large and heavy.

The ultrasonic techniques were used for therapeutic and diagnostic applications as well as for cleaning of instruments before sterilization, its main use is for scaling and root planing in periodontology and in root canal therapy, both for orthograde and retrograde therapy, in prophylactic procedures, tissue regeneration, and oral surgery techniques. $[4][5][6][7][8][9]$.

When ultrasound or ultrasonic instrumentation was born, it was primarily intended for the cavity preparations. Despite receiving favourable opinions, the technique was never widely applied as it had to compete with the more efficient high-speed handpiece. Only in 1955 Zinner introduced ultrasound technology in periodontology suggesting its use for removal of debris from the tooth surface (scaling). By 1960 Johnson and Wilson improved the ultrasound technique and it became an established tool in the periodontal field in the removal of tartar and plaque. (10)

The concept of using US in endodontics was first introduced by Richman (11) in 1957. However, it was not until Howard Martin et al in $1976(12,13,14)$ demonstrated the ability of ultrasonically activated K-type files to cut dentin that this application found common use in the preparation of root 
canals before filling and also obturation. The term endosonics was coined by Martin and Cunningham $(15,16)$ and was defined as the ultrasonic and synergistic system of root canal instrumentation and disinfection.(17)

In 1970 the ultrasonic technology found a field of application in treatment of TMJ dysfunction and in measurement of translatory movements of the condyle during motion. In 1976 Martin published his first paper on increasing the efficacy of bactericidal root canal irrigation if associated with ultrasonic technique. In the same year Bertrand et al published an article about what is presumed to be the first use of a modified ultrasonic tip for a retropreparation during an apicoectomy. In 1980, Martin et al. discovered an increase in the cutting capacity of a k-files, activated by ultrasound and emphasized its potential for use in root canal preparation before filling. In 1984-85 Martin and Cunningham coined the term 'endosonic' to define the synergistic action of instrumentation and disinfection the root canal system by ultrasonics. Around 1990s, after the introduction of the first ultrasonic tips by Gary Carr, the focus shifted to the use and possible consequences of ultrasonic root-end preparations during apicoectomy. The introduction of the piezoelectric device and numerous drawings of ultrasonic tips after 1990 has allowed clinicians to remove dentin or other dental materials in a very controlled and precise manner, using tips that are often approximately the same size as a root canal or smaller. In the same time were introduced in the market tips designed to deliver vibrational energy in a focused manner, without the intention to cut tooth structure. (10)

Ultrasound is sound energy with a frequency above the range of human hearing, which is $20 \mathrm{kHz}$. The range of frequencies employed in the original ultrasonic units was between 25 and $40 \mathrm{kHz}$ (18). Subsequently the so-called low-frequency ultrasonic handpieces operating from 1 to $8 \mathrm{kHz}$ were developed $(19,20)$, which produce lower shear stresses $(21)$, thus causing less alteration to the tooth surface (22). The first devices were simply a modification of existing equipment: e.g. the Cavi-Endo was based on the Cavitron. The early instruments were sensitive to vibrations and during ultrasonic preparation of root canals the cutting motion of the file was completely uncontrolled, leading to possible damage in the apical part of the canal and an irregular canal wall.(23)

Modern ultrasonic units propose both high power and precision cutting and enable control not only of the frequency but also of the vibration amplitude. Qualitative improvement of ultrasonic units and the increased availability of new tips goes hand in hand with the refinement of endodontic technique, which is likewise constantly progressing. Endodontics is the specialization in which ultrasound has enabled the most visible progress to be made, and some stages of endodontic technique have even been modified, above all when the use of ultrasonic tips is associated with that of the operative microscope; for this reason state-of-the-art endodontics cannot today neglect these two fundamental instruments.(c)

We have evolved in endodontics from sonics to ultrasonics to now piezo electric ultrasonics. In modern endodontics, when we talk of ultrasonics, we really mean piezo electric ultrasonics. Basically ultrasonic endodontic devices work by converting electromagnetic energy to mechanical energy.
There are two basic methods of producing ultrasound (24 26).

\section{Magnetostriction Technology}

Magnetostriction converts electromagnetic energy into mechanical energy. A stack of magnetostrictive metal strips in a handpiece is subjected to a standing and alternating magnetic field, as a result of which vibrations are produced. A magnetostrictive device creates more of an elliptical motion, which is not ideal for either surgical or nonsurgical endodontic use and have also the disadvantage that the stack generates heat, thus requiring adequate cooling.

\section{Piezoeletric Technology}

Based on the piezoelectric principle, which uses a crystal that changes dimension when an electrical charge is applied. Deformation of this crystal is converted into mechanical oscillation without heat production. Piezoelectric units have two advantages with respect to earlier magnetostrictive as they offer "cycles" per second (40,000 CPS versus 24,000 CPS), and secondly, the tips of these units work in a linear, back-and-forth "piston-like" movement. Its motion is ideal for endodontics. This is particularly evident when removing posts and separated instruments. Additionally, in surgical endodontics, this motion is ideal for creating a retropreparation. (27)

\section{Mechanism of Action}

\section{Cavitation}

2. Acoustic Streaming

Cavitation: Is defined as the growth and subsequent violent collapse of a small gas-filled pre-existing in-homogencity in the bulk fluid. This motion results in development of shock wave increased temperature and prsssure and free radical formation in the fluid. Useful during scaling procedures in removing tooth deposits but of limited use in root canal therapy.

Acoustic Streaming: Is defined as the generation of time independent, steady unidirectional circulation of fluid in the vicinity of a small vibrating object. this flow of liquid has a small velocity, of the order of a few centimetres per second, but because of the small dimensions involved the rate of change of velocity is high. this results in the production of large hydrodynamic shear stresses around the file which are more than capable of disrupting most biological materials.(28)

Besides ultrasonic devices, also sonic instruments are used in endodontics, with a frequency from 1500 to $6000 \mathrm{hz}$ (MicroMega Sonic Air, KaVo SonicFlex Endo) for detection and preparation of the canal orifices, for removal of soft materials and for canal preparation with continuous irrigation. Another sonic device (EndoActivator) is used to activate intra-canal irrigants during endodontic treatment. Piezosurgery devices have been developed for bone surgery, and have found applications in endodontic surgery, for osteotomy, root-end resection and retropreparation. A recent literature review (Abella JOE 2014) found no published data on the effect of piezosurgery on the outcomes of endodontic surgery; no study has evaluated the effect of piezosurgery on root-end resection, and only one has investigated root-end morphology after retrograde cavity preparation using piezosurgery. From anecdotical reports, it looks that piezosurgery results in less bleeding, less swelling and less postoperative pain.(10) 
Table No. 1 describes most frequent applications of ultrasonic in endodontics. (29)

Table No 1 Most Frequent Applications of Ultrasonic in Endodontics

\begin{tabular}{cc}
\hline Serial\# & Application \\
\hline 1 & Access refinement, finding canals with calcification and pulp \\
stone removal \\
2 & $\begin{array}{c}\text { Removal of intra canal obstructions (separated instruments } \\
\text {,root canal posts, silver points, and fractured metallic post) } \\
\text { Root canal preparation. }\end{array}$ \\
4 & Increased action of irrigating solutions. \\
5 & Ultrasonic condensation of gutta-percha. \\
6 & Distribution of sealer around the root canal walls - \\
7 & Placement of mineral trioxide aggregate (MTA). \\
8 & Surgical endodontics: Root-end cavity preparation and \\
& refinement and placement of root-end obturation material. \\
\end{tabular}

The primary endodontic treatment goal is to optimize root canal disinfection ensuring prevention of re-infection. Microorganisms, either remaining in the root canal space after treatment or re-colonizing the filled canal system, are the main cause of endodontic failure. (30) Primary root canal infections are polymicrobial, typically dominated by obligatory anaerobic bacteria, Gram-negative anaerobic rods, Gram-positive anaerobic cocci, Gram-positive anaerobic and facultative rods, Lactobacillus species and Gram-positive facultative Streptococcus species.(31) The obligate anaerobes are rather easily eradicated during root canal treatment. On the contrary, facultative bacteria, such as nonmutans Streptococci, Enterococci and Lactobacilli, once established, are more likely to survive chemo-mechanical instrumentation and root canal medication. (32) US creates both cavitation and acoustic streaming. The cavitation is minimal and is restricted to the tip. The acoustic streaming effect, however, is significant.(33) Studies have shown ultrasonic preparation with ultrasonic irrigation devices have significantly cleaner canals than teeth prepared by conventional root canal filing alone.(34)

Instrumentation in endodontics has now reached strategic levels, and the qualitative improvement of ultrasonic units and the increased availability of newer $\&$ variety of tips goes hand in hand with the refinement of endodontic technique, which too likewise is constantly evolving. Consequently, recent years have seen the introduction of more and more highly developed ultrasonic sources that enable optimal utilization of all the varied tips available, demanding specific methods of use. For this reason, modern ultrasonic units propose both high-power and precision cutting as well as enable control not only of the frequency but also of the vibration amplitude. As a consequence, it is very important that the ultrasonic source is specifically dedicated to endodontics or it is a multipurpose unit offering an "endo" application, in which the amplitude of the vibrations is limited.

\section{Endosonic units may be}

1. A very simple unit, ergonomically easy to place, being small and compact, but one that provides a wide range of uses in the endodontic field with the possibility of varying its operative frequency extensively and precisely.

2. A more sophisticated and recent one which uses new technology that allows the unit and its power to be set automatically, according to the tip used, optimizing the action of the tip, decreasing the stress and increasing the life of the tip.

Handpieces have threads of different pitches (E-thread and an S-thread are currently used); Consequently, one needs to avoid "closed" systems which allow mounting of tips specifically produced only for that machine or systems in which the use of other tips is complex. One should prefer "open" systems in which allows use of almost all types of available tips. Increasing clinical demands have lead to evolving of ultrasonic tips in parallel with endodontic techniques and have also inevitably increased in number, though they differ not only in shape and length but also in the material from which they are made. Thanks to growing technology, for years the only metal used was steel, with which many excellent tips are produced that are still being used profitably today with even higher performance, e.g. the new Pro-Ultra tips, coated with zirconium nitride, and those of the Pro-Ultra series made of titanium. Many of the tips incorporate a built-in water port so that debris can be washed away with cooling effect. However, we must be able to control the power supplied by the ultrasonic source very precisely, which confirms how important it is to have a good unit available, not only to use the tips to the best, optimizing their performance, but also to minimize tip breakages.(35)

\section{Types of tips}

\section{Ultrasonic files}

The endodontic instruments as K-files mounted on Endochuck or as independent files inserts may be used for:

- Activation of irrigants to increase its effectiveness

- Removal of obstacles intra-canal, especially those positioned in the medium-apical third of the canal (like broken files)

- Allow the achieving and positioning of MTA in the apical third of the canal

\section{Stainless Steel/Nickel Titanium}

The ultrasonic tips Nickel-Titanium are much more fragile than stainless-steel, are used to work at a low intensity within the canal. They should be activated when in contact with the canal walls otherwise they tend to fracture.

\section{Surgical Endodontics Tips}

Ultrasonic technique has opened many arenas in endodontic microsurgery, along with magnification and coaxial illumination using specially designed ultrasonic tips for rootend preparation, allowing an accurate, centered and deep preparation of the canal.

\section{Active tip/Smooth tip}

The active tip makes an extremely effective tool when used for fiber posts and obstacles present in pulp chamber removal and in all conditions in which there is good view and low risk of creating iatrogenic injury.

The smooth tip is useful when cutting action is not necessary on the tip but is exerted by the body of the instrument, useful in pulp stone and intra-canal obstructions (such as post) removal. 


\section{Diamond-coated/Non-Diamond coated}

The diamond coating of an ultrasonic tip makes it much more effective and abrasive.

This kind of tip, especially if used without irrigation, tends to get soiled with dentinal debris thus losing cutting efficacy and the diamond part, overtime, gets consumed and detached.

Surface coatings on ultrasonic tips are intended to increase efficiency and durability; diamond-coated tips seem to require less time than stainless-steel tips or zirconium nitride tips to cut similar preparations.

\section{Smooth/Milled}

Among the uncoated diamond tips we can find those with a smooth surface and those milled surface. The tips with milled surface have a higher lateral cutting ability and longer lasting even compared to the coated diamond tips.

The choice of each tip type (active/non active, smooth/milled), the intensity of use, and use with or without water is in close relationship with the area in which it will work.

Table No 2 Clinical Classification according to the tooth section in which they operate.

\begin{tabular}{|c|c|c|}
\hline Serial\# & $\begin{array}{c}\text { Operating Tooth } \\
\text { Section }\end{array}$ & Action \\
\hline 1 & Pulp Chamber & $\begin{array}{l}\text { Access refinement, finding calcified } \\
\text { canals, removal of pulp stones }\end{array}$ \\
\hline 2 & $\begin{array}{c}\text { Coronal \& Middle- } \\
\text { Third }\end{array}$ & $\begin{array}{c}\text { Removal of intra-canal obstructions: } \\
\text { - separated instruments } \\
\text { - root canal posts } \\
\text { - fractured metallic posts } \\
\text { Increased action of irrigating solutions } \\
\text { Placing of MTA }\end{array}$ \\
\hline 3 & Apical-Third Canal & Surgical Endodontics \\
\hline
\end{tabular}

\section{Pulp chamber}

\section{Access refinement}

The current modern endodontic guidelines aim towards the execution of a minimally invasive access cavity allowing the operator on one hand a straight access to the canal entrances, but also sparing as much of the tooth structure, in this respect, realization of a modern access concept. First phase of penetration, coarse enlargement, refinement and extension of the cavity are performed in full with ultrasonic tips. Specially designed tips for the preparation of the coronal third of the root canal are available, which can be used in combination with a surgical microscope for improved vision.

Advantages: Cutting effectiveness and precision towards dentin and visibility allowed by the absence of the head of the micro-motor and good control without damaging the floor of the pulp chamber, especially when sclerotic or almost absent.

Selection of tip - for the gross removal of dentin in an access preparation, an ultrasonic tip with a length suitable for most access preparations with strong tip that is less prone to fracture and an abrasive grit along half of its length is recommended. For effective functioning of tips they must be set from a maximum to average intensity value, alternating the irrigation phase and dry phase to avoid overheating.

\section{Pulp Stones}

When a pulp stone occludes the entrance to a canal orifice, use of ultrasonic tips that have a disc-like working part is recommended, due to their ability in erosion of attached pulp stones; used with a brush-like motion without gauging the floor carefully smoothening the pulp stone away. It is very important to use inserts that would not interfere with the floor of the pulp chamber not only to prevent iatrogenic damage (perforations), but also not to miss position of the root canals. The tips should be used effectively and set from a maximum to average intensity value, alternating the irrigation phase and dry phase to avoid overheating.

\section{Calcified Canals}

In all the circumstances in which it is required to explore grooves and isthmuses to find hidden and calcified canals such as MB2 in the maxillary molars or sclerotic canals in traumatic teeth the use of dedicated ultrasonic tips is recommended; untreated root canal anatomy is likely cause of long-term failure of endodontic treatment. In such situations roughing bigger tips with a limited diamond-coated extension should be used during the initial phase of removing calcification, interferences, materials, and secondary dentin, as they offer maximum cutting efficiency and enhance control while working in the pulp chamber. The phase of finding canal orifices should be done with thinner and longer tips that allow working in deeper areas while maintaining clear vision avoiding iatrogenic injury such as coronal-middle perforations.

\section{Coronal-Middle Third of the Canal}

Ultrasonic tips are useful to remove foreign objects in the upper and middle portion of the root canal, like posts, hard cement, silver points, and separated instruments. A diamondor abrasive-coated tip can be used for gross dentin removal, to obtain a straight-line access under magnification and coaxial illumination; smooth surface tips are less aggressive and can be used in the deeper portions of the root canal. Ultrasonic tips should be used with a light touch and be kept moving during use, starting with lowest power setting, and increased as needed. Overheating of the tip and of the tooth structure is prevented with intermittent activation of ultrasonics, with copious air coolant; water can be used to cool the tip and remove debris, though it impairs the clear vision of the operating field. Some tips have a water port for cooling, and some are designed to work dry.

\section{Silver Points and Separated Files}

Silver tips were used as a filling material some time ago; their removal can be easy when a portion of the tip is reachable by a dedicated plier, named Stieglitz forceps, but can be very when deeply buried in the canal, a thin ultrasonic tip can be helpful for silver point removal. Silver points are very fragile, so the ultrasound tip should be used at very low power, with light pressure and should work more on dentin than on the silver point itself. Similar technique is used for removal of broken instruments eventually vibrating it out. Tips made of a new alloy, Titanium-Niobium, have recently been marketed for retrieval of broken instruments.

\section{Apical Third of the Canal}

In the apical portion of the canal, dedicated tips should be used. Besides the Titanium-Niobium tips cited above, titanium alloys are often used for this application, and the tips are smooth, non-coated. These tips can be bended; used at low power setting with very light pressure. Any excessive force 
or power easily fractures these instruments. These tips can be used at minimal power, for vibrating MTA cement as also by applying a bigger ultrasonic tip to an endodontic plugger. (36)

Due to the complex anatomy, complete cleaning and shaping of the root canal system is impossible with just files or reamers (37) even with newer, advanced instruments made of nickel-titanium (NiTi). Furthermore instrumentation produces a smear layer and dentine debris in the root canal, which has to be removed by irrigation, (38) making it an essential aspect of root canal therapy (39).

"Instruments shape, irrigants clean." Irrigation is made effective by placing an ultrasonic tip into the bleach that is in the chamber, hence, enhancing the cleaning efficacy of our irrigation agent. This is because the ultrasonic creates both cavitation and acoustic streaming.

During passive ultrasonic irrigation (PUI), a small ultrasonically oscillating file or smooth wire (e.g. size 15, 20) is placed in the centre of the root canal, following canal shaping, to transmit the energy of the file as efficiently as possible to the irrigant. As a result, acoustic micro-streaming and/or cavitation occurs $(40,41)$. The irrigant flows through the canal and the file or wire vibrates freely. The file has a nodal and antinodal pattern, which also occurs on a precurved file, partly explaining the efficacy of PUI in curved canals (42). PUI, with sodium hypochlorite $(\mathrm{NaOCl})$ as irrigant, removes more dentine debris, planktonic bacteria and pulp tissue from the root canal than manual syringe irrigation (43) enhancing the antibacterial and organic tissue dissolving potential of $\mathrm{NaOCl}$ through temperature increment(44) and a more active streaming pattern.

Two flushing methods can be used during PUI:

1. Continuous flushing of irrigant from the ultrasonic hand-piece.

2. Intermittent flush method using a syringe (44). In the intermittent flush method, the irrigant is delivered into the root canal manually with a syringe, and refreshed after each ultrasonic activation.

During ultrasonic activation, microorganisms, dentine debris or organic tissue can be detached from the root canal wall and is absorbed or dissolved in the irrigant (45). Hereafter, the root canal is flushed with $2 \mathrm{ml}$ of fresh irrigant to remove remnants from the root canal.

A disadvantage with the use of a $\mathrm{NaOCl}$ solution is that the reservoir of the ultrasonic machine accumulates corrosive products and sodium salts would clog-up and even corrode the tubes. Hence, after the use of $\mathrm{NaOCl}$, the machine, the tubes and the hand-piece are flushed with demineralised water. With careful maintenance and by using $\mathrm{NaOCl}$ at concentrations no higher than $5 \%$, most of the equipment function trouble free.

\section{Ultrasonic condensation of gutta-percha}

Ultrasonically activated spreaders have been used to thermoplasticize gutta-percha in a warm lateral condensation technique. Initial placement of a gutta-percha cone to the working length is followed by lateral condensation of two or three accessory cones using a finger spreader (46). The ultrasonic spreader is then placed into the center of the gutta-percha mass, $1 \mathrm{~mm}$ short of the working length and activated at intermediate power. After activation, the ultrasonic spreader is removed, and an additional accessory cone is placed, followed by energizing with the activated ultrasonic spreader. The spreader must be in a canal for only 10 seconds for best results $(47,48)$.

\section{Surgical Endodontics}

Dedicated tips for apical retropreparation allows the access for $3 \mathrm{~mm}$ or more in the apical portion of the canal, including isthmuses and deep placement of filling material in the canal, thereby enhancing the predictability of the procedure. Powerful endodontic devices, such as Piezosurgery ${ }^{\circledR}$, can be used for bone access and for retropreparation

\section{Enhancement of dentine permeability during non-vital bleaching}

Internal bleaching to lighten teeth provides good results at relatively low cost. The action of an internal bleaching agent is dependent on its ability to penetrate into dentinal tubules and by means of oxidation-reduction reaction, modifies the pigments that caused the chromatic alteration of the dentine substrate. Ultrasonic activation of an irrigant, $1 \% \mathrm{NaOCl}$ or $17 \%$ EDTA, in the pulp chamber can significantly increase dentine permeabil- ity(49). The irrigant is placed in the pulp chamber and then ultrasonically activated for 15 seconds and this procedure repeated three times. An ultrasonic tip (e.g. one to remove calculus) is used without touching the cavity walls. After this procedure the bleaching agent can then be applied.

\section{References}

1. Ultrasonic energy: a possible dental application. Preliminary report of an ultrasonic cutting method; Catuna MC; Ann Dent 1953;12:256-60.

2. Ultrasonic cavity preparation; Postle HH; J Prosthet Dent 1958;8:153- 60.

3. The application of ultrasonic energy in the dental field. In: Brown B, Gordon D, eds. Ultrasonic techniques in biology and medicine. London: Ilife; Balamuth L. 1967:194 -205.

4. Surgical Endodontics; Carrote, P; British Dental Journal 198, 71 - 79 (2005).

5. Ultrasonics in endodontic surgery: a review of the literature, Ann Stomatol (Roma);De Paolis Gianfranco, Vincenti Valentina, Prencipe Matteo, Milana Valerio, Plotino Gianluca; 2010 Apr-Jun;1(2):6-10.

6. Ultrasonics in endodontics: a review of the literature; Plotino G., Pameijer CH, Grande NM, Somma F; J Endod. 2007 Feb;33(2):81-95

7. Ultrasounds in periodontics; Sapna N, Vandana K N, IJDA, 2(3), July-September, 2010, p. 274-277.

8. Therapeutic ultrasound for dental tissue repair, Medical Hypotheses; Scheven B.A.A., Shelton, R.M., Cooper, P.R., Walmsley, A.D., Smith, A.J.; Volume 73, Issue 4, p. 591-593, (2009).

9. Applications of ultrasounds in dentistry, Ultrasound Med Biol.; Walmsley, AD; 1988; 14(1):7-14.

10. Enrico-Cassai-Ultrasonics-in-Endodontics-Part-1-viawww.styleitaliano.org

11. The use of ultrasonics in root canal therapy and root resection; Richman RJ; Med Dent J. 1957; 12:12-18.

12. Ultrasonic disinfection of the root canal. Oral Surg Oral Med Oral pathol; Martin H; 1976; 42:92-99.

13. Ultrasonic versus hand filing of dentin: a quantitative study; Martin H, Cunningham WT, Norris JP, Cotton 
WR; Oral Surg, Oral Med Oral Pathol. 1980; 49:7981.

14. A quantitative comparison of the ability of diamond and K-type files to remove dentin. Oral Surg Oral; Martin H, Cunningham WT, Norris JP; Med Oral Pathol. 1980;50: 566-568.

15. Endosonic endodontics: the ultrasonic synergistic system; Martin H, Cunningham W; Int Dent $J$. 1984;34:198-203.

16. Endosonics: the ultrasonic synergistic system of endodontics. Endod Dent Traumatol; Martin H, Cunningham W; 1985; 1:201-206.

17. Ultrasonics in endodontic surgery: a review of the literature Annali di Stomatologia 2010; I (2): 6-10 7 Ultrasonics in endodontic surgery: a review of the literature

18. Current status of the use of ultrasound in endodontics; Stock CJR; Int Dent J 1991; 41:175- 82.

19. La technique de l'appui parietal (T.A.P.) Rev Franc; Laurichesse JM; Endod 1985; 4:19 -38.

20. Root-end cavity preparation after apicoectomy using a new type of sonic and diamond-surfaced retrotip: a 1year follow-up study; von Arx T, Kurt B; J Oral MaxillofacSurg 1999; 57:656-61.

21. Ultrasonic debridement of root canals: an insight into the mechanisms involved; Ahmad M, Pitt Ford TR, Crum LA; J Endod 1987;13:93-101.

22. Evaluation of cracks associated with ultrasonic rootend preparation; Layton CA, Marshall JG, Morgan LA, Baumgartner JC; J Endod 1996;22:157- 60.

23. Ultrasound in endodontics; Luc van der Sluis; ENDO 2007; 1(1):29-36

24. Ultrasound and root canal treatment: the need for scientific evaluation; Walmsley AD; Int Endod J 1987; 20:105-11.

25. An investigation into the occurrence of avitational activity during endosonic instrumentation; Lumley PJ, Walmsley AD, Laird WRE; J Dent 1988;16:120-2.

26. Ultrasound in dentistry: Part1 Biophysical interactions; Laird WRE, Walmsley AD; J Dent 1991;19:14-7.

27. The Endo Advantage - Kenneth Koch, DMD, and Dennis Brave, DDS; www.dentaleconomics.com/ articles/print/volume-91/issue.../the-endo advantage.htm

28. https://books.google.co.in/books?isbn=9350909529; Nisha Garg, Amit Garg - 2013 - Medical

29. Modern Concepts of Ultrasonic Root Canal Irrigation; (e) Dalai DR, Bhaskar DJ, Agali CR, Singh N, Singh H; Int J Adv Health Sci 2014; 1(4):1-4; August 2014 | Vol 1 | Issue 4

30. The use of ultrasonics in the removal of the smear layer: a scanning electron microscope study; Cameron JA; J Endodont 1983 July;9(7):289-292.

31. A new insight into the oscillation characteristics of endosonic files used in dentistry; Lea SC, Walmsley AD, Lumley PJ, Landini G; Phy Med Biol 2004 May;49(10):2095-2102.
32. In vivo debridement efficacy of ultrasonic irrigation following hand rotary instrumentation in human mandibular molars; Gutarts R, Nusstein J, Reader A, Beck M; J Endod 2005 Apr;31(3):166-170.

33. Factors affecting the clinical efficiency of ultrasonic endodontics: a scanning electron microscopy study; Cameron JA; Int Endod J 1995; 28(1):47-53.

34. Jensen SA, Walker ThL, Hutter JW, Nicoli BK. Comparison of the cleaning efficacy of passive sonic activation and passive ultrasonic activation after hand instrumentation in molar root canals. J Endod 1999 Nov; 25(11):735-738.

35. The Use of Ultrasound in Endodontics; Author_Fabio Gorni, Italy; dente_de_Roots_instruments.pdf

36. ULTRASONICS IN ENDODONTICS: PART 2; http://www.styleitaliano.org/ultrasonics-inendodontics-part-1

37. Current challenges and concepts in the preparation of root canal systems: a review; Peters OA; $J$ Endod 2004;30: 559-567.

38. Mechanical preparation of root canals: shaping goals, techniques and means; Hülsmann M, Peters OA, Dummer PMH; Endod Topics 2005;10:30-76.

39. Eradication of endodontic infection by instrumentation and irrigation solutions; Haapasalo M, Endal U, Zandi H, Coil JM; Endod Topics 2005;10:77-102.

40. Ultrasonic debridement of root canals: acoustic streaming and its possible role; Ahmad M, Pitt Ford TR, Crum LA; J Endod 1987;14:490-499.

41. Physical mechanisms governing the hydrodynamic response of an oscillating ultrasonic file; Roy RA, Ahmad M, Crum LA; Int Endod J 1994;27:197-207.

42. Effect of precurving endosonic files on the amount of debris and smear layer remaining in curved root canals; Lumley PJ, Walmsey AD, Walton RE, Rippin JW; $J$ Endod 1992; 18:616-619.

43. Passive ultrasonic irrigation of the root canal: a review of the literature; van der Sluis LWM, Versluis M, Wu MK, Wesselink PR; Int Endod J, in press.

44. The effect of ultrasonic endodontics on the temperature of the root canal wall; Cameron JA; J Endod 1988; 14:554-558.

45. The influence of volume, type of irrigant and flushing method on removing artificially placed dentine debris from the apical root canal during passive ultrasonic irrigation; van der Sluis LWM, Gambarini G, Wu MK, Wesselink PR; Int Endod J 2006; 39:472-477.

46. Custom fitting of standardized gutta-percha master cones; Knapp JP, Marshall FJ; Dent Digest 1972; 78:348-52.

47. Radiographic evaluation of extruded obturation materials; Augsburger RA, Peters DD; J Endod 1990; 16:492-7.

48. Comparison of gutta-percha filling techniques, compaction (mechanical), vertical (warm), and lateral condensation techniques; Wong M, Peters DD, Lorton L; Part I. J Endod 1981;7:551-8.

49. In vitro assessment of dentin permeability after the use of ultrasonic activated irrigants in the pulp chamber before internal dental bleaching; Carasco LD, Pécora JD, Fröner IC; Dent Traumatol 2004;20:164-168. 